\section{Comparison of Presentation Method Effectiveness for Dissemination of Pesticide- free Turfgrass Management Information}

\author{
Julie H. Campbell ${ }^{1,4}$, Jason J. Henderson ${ }^{2}$, and Victoria H. Wallace ${ }^{3}$
}

ADDITIONAL INDEX WORDs. knowledge retention, survey

\begin{abstract}
SUMMARY. This study examined how different presentation formats affected knowledge gain among school grounds managers. Results indicate large-group participants (presentation to $\approx \mathbf{5 0}$ participants at a turfgrass field day) had greater knowledge retention than small-group participants (presentation to 6-10 participants at an interactive workshop). Small-group attendees had more flexibility to discuss issues that affected them directly and may have focused on those issues instead of the targeted information. Large-group meetings were more ridged in format and attendees were less able to deviate from the main subject matter being presented. However, the value of the small-group meeting should not be discounted, especially when athletic field grounds managers and staff require information specific to their situation. When disseminating more general information, the large-group meeting format is a better means of delivery.
\end{abstract}

$\mathrm{P}$ esticide use on school properties is under increased scrutiny because of health and safety concerns of school-age children and staff (Alarcon et al., 2005; Gilden et al., 2012), as well as environmental concerns (Edwards, 1993; Matson et al., 1997; Pimentel et al., 1992). New laws banning or restricting pesticide use on school properties, coupled with budget reductions, have severely reduced the ability of turfgrass managers to manage pests (Miller and Henderson, 2012). Sports fields included in this law are at an elevated risk for poor playingsurface quality (Dest and Ebdon, 2011; Henderson et al., 2013; Miller and Henderson, 2012). The state of Connecticut banned pesticides on kindergarten-eighth grade (K-8) school grounds, private schools, and daycare centers (State of Connecticut, 2005). A majority (77\%) of Connecticut school grounds/athletic field managers (hereafter referred to as school grounds managers) have perceived a decrease in the quality of fields they manage since Connecticut

\footnotetext{
${ }^{1}$ Department of Horticulture, University of Georgia, 325 Hoke Smith Building, Athens, GA 30602

${ }^{2}$ Department of Plant Science and Landscape Architecture, University of Connecticut, 1376 Storrs Road, Unit 4067, Storrs, CT 06269

${ }^{3}$ Department of Extension, University of Connecticut, 562 New London Turnpike, Norwich, CT 06360 ${ }^{4}$ Corresponding author. E-mail: julie.campbell@uga. edu.
}

https://doi.org/10.21273/HORTTECH04019-18 introduced the pesticide ban in 2010 (Bartholomew et al., 2015).

Given these restrictions, school grounds management staff must be proactive in adopting alternative management practices to maintain athletic field quality or risk the potential for increased injuries associated with poor playing surface quality (Chomiak et al., 2000; Harper et al., 1984; Orchard, 2002). Since the pesticide ban became effective in Connecticut, the move toward alternative practices has been very limited. Only a small percentage of school grounds managers have embraced alternative management practices (i.e., overseeding, use of minimum-risk products exempt from federal registration, etc.) in response to the pesticide ban (Wallace et al., 2016). This failure to embrace alternative management practices is most likely because of budgetary constraints and a lack of education associated with alternative methods. Extension programs and educational workshops can educate grounds managers on alternative pesticide-free management practices and therefore, directly improve the quality of school grounds/athletic fields (Bartholomew et al., 2015). It is imperative to understand both the current level of knowledge, and the most effective dissemination methods to facilitate information uptake and retention by school grounds managers. The recently implemented pesticide ban on K-8 schools within the state and the lack of adoption of new management practices (Wallace et al., 2016) makes Connecticut a unique environment to test preexisting knowledge and the effectiveness of different educational programming.

Based on previous research, the most widely used evaluation tools to examine knowledge gains from educational programs are pre- and postsurveys or tests. Traditionally, participants are asked questions at the beginning of a program (pretest) and after information has been disseminated (posttest). The design has been used to examine several measurable changes, including participant knowledge, attitudes, or behaviors. Pretest/posttest mechanisms have been shown to be well suited to investigate education programs (Dugard and Todman, 1995; La Barge, 2007).

Several studies have evaluated dissemination mechanisms to identify how effective presentation methods are for educational programming. Kline et al. (2012) used various program dissemination mechanisms that targeted varied clientele, including Amish producers. Results indicated positive feedback on the targeted programs using a poster format along with discussion. Mathiasen et al. (2012) used a 12-min training video to improve agricultural workers' knowledge of food safety. Shaw et al. (2015) taught a 7-h good agricultural practices (GAP) course that included a mix of discussion, traditional computer based delivery presentations, and case studies, and found improved knowledge gain about food safety with participating Iowa producers. Nayak et al. (2015) used pre and posttests to examine knowledge gain associated with their training curriculum on GAP for Pennsylvania commercial buyers. Training increased their growers' GAP knowledge by $22 \%$. Cutz et al. (2015) examined knowledge gains of students participating in after-school extension programs. Students gained knowledge across gardening, technology, and composting programs. Focusing on turfgrass information dissemination methods, Kennelly and Hoyle (2015) note that e-mail was the most preferred method to receive information of Kansas turfgrass professionals (i.e., golf course managers, lawn care companies, chemical companies, school grounds managers, etc.). 
Traditional lecture format (i.e., presenter at podium, chalkboard, handouts, etc.) has been found to increase retention by university students compared with computer based presentation formats (Amare, 2006; Savoy et al., 2008). Research has found positive, negative, and no relationship between class size and student achievement (Nyhan and Alkadry, 1999). Educator workshops, short presentations, and DVD formats have been compared as methods to increase implementation of an urban environmental education program (Kudryavtsev et al., 2010). Workshop dissemination was the most successful method for increasing implementation of the program by attendants. However, there is some evidence that there is no difference between problembased learning (similar to small-group interactive workshops) and lectures (similar to large-group field day) (Beers, 2005).

Results from all cited research indicate that regardless of new technologies and methods to disseminate information, the conventional methods of large-group field days and small-group interactive workshops are still critical to many agricultural producers/managers. Producers still highly value one-on-one contact, so that they are able to have a dialogue and allow for problem solving during the dissemination process (Milburn et al., 2010). In addition, workshops enable participants to share their experiences and provide the opportunity to question instructors and other participants, which fosters peer-topeer learning.

The objective of this research was to determine the effect of dissemination method on knowledge retention of school grounds managers. For the remainder of this article, we refer to the interactive workshop as "smallgroup" and the presentation at a turfgrass field day as "large-group" setting. Our hypothesis was that there would be different knowledge gains between the small-group setting and the large-group setting. We further anticipated certain manager characteristics would influence knowledge gained by school grounds managers and staff.

\section{Materials and methods}

Two information dissemination programs (small-group setting and large-group setting) were developed to assess the level of knowledge gain of school grounds manager professionals on a variety of turfgrass topics. The large-group setting was a lecture style field day, conducted outdoors at research and demonstration plots involving pesticide-free athletic field management practices. The smallgroup setting was an interactive workshop that allowed for discussion about hands-on demonstrations of best management practices for pesticide-free athletic fields. The content of each of the programs was similar, covering topics that included: mowing, fertilization, irrigation, cultivation, pest control, aeration, compost topdressing, and overseeding.

A pre- and postsurvey was developed to measure information retention of attendees participating in each program (large and small). Before initiating this research, the program and survey were approved by the university's internal review board. The survey consisted of questions relating to personal characteristics of the school grounds manager (i.e., number of years on the job, prejob training, training on the job, types of daily management duties performed, etc.), departmental characteristics (i.e., number and types of grounds maintained, current maintenance practices, etc.), and four questions related to the main topics of the subsequent educational program. The four questions were focused on athletic field management practices covered: 1) irrigation, 2) aeration, 3) compost topdressing, and 4) aggressive overseeding (Table 1 ). The survey was also vetted by numerous University of Connecticut faculty members within the Department of Plant Science and Landscape Architecture, Department of Education, and Department of Extension before implementation.

All small- and large-group presentations occurred between Aug. and Oct. 2015, with a focused interest on school grounds managers throughout the state of Connecticut. Small-group meetings consisted of university researchers and extension faculty traveling to several school districts throughout the state to meet with a variety of school grounds managers and their staff. Staff employees were also included in the small-group workshop format because this format provides a unique opportunity to educate both decision makers and non-decision makers. Meetings at each school district occurred separately. Small-group presentations were held for three school districts and had 6-10 participants in each meeting, providing for a total of 24 useable surveys. Information was disseminated over a 4-to 5-h time frame. Districts were chosen based on interest in participation and staff availability. Large-group presentation corresponded with a single turfgrass field day specifically developed for school grounds managers held at the University of Connecticut Plant Science and Landscape Architecture Research and Education Facility in Storrs. About 50 participants attended, with 22 participants providing useable surveys. Surveys were only completed by school grounds managers and their staff. Survey participants from small and large group presentations did not overlap. Presentation information was presented over $\approx 1.5 \mathrm{~h}$. Characteristics of professionals completing the pre- and postsurveys for participants at large- and small-group meetings can be found in Table 2.

Overall educational material presented during the two events was the same. For participants in both smalland large-group meetings, pretests were given on arrival at the venue. Posttests were given immediately after all information was presented. Smallgroup meetings were designed with the following format: explanation of a document which covered best management practices for pesticide-free, cool-season athletic fields (Henderson et al., 2013), group discussion, and then a demonstration of aeration and overseeding techniques. Large-group setting took the following format: short lecture presentation on best management practices for pesticide-free athletic fields, questions and answers, and an explanation of various equipment importance and functionality for managing pesticide-free athletic fields. Discussions in the large group revolved around central topics, as covered by the survey knowledge questions. However, discussion in small-group meetings often branched into other areas, as attendees asked questions on a variety of topics specific to their situations.

Small-group and large-group differences in continuous variables 
Table 1. Survey questions used for knowledge assessment in a 2015 survey of Connecticut turfgrass professionals.

Which of the following statement is most correct?

Irrigation is not important for maintaining high quality fields and should not be used.

Irrigation should be used when the soil is completely dry to the touch.

Irrigation should be used when plants are just beginning to show signs of moisture stress.

An automated program should be run consistently regardless of weather conditions.

I do not know

Which of the following statements is most correct about when kindergarten-eighth grade athletic fields should be aerated?

Kindergarten-eighth grade athletic fields should never be aerated.

Kindergarten-eighth grade athletic fields should be aerated every other year to give the field a chance to firm up.

Kindergarten-eighth grade athletic fields should be aerated every year in the spring to increase infiltration rates and prepare a seedbed for re-establishment.

Kindergarten-eighth grade athletic fields should be aerated every year in the fall to encourage gas exchange and potentially kill white grubs.

Kindergarten-eighth grade athletic fields should be aerated every year in either the spring or fall depending level of traffic on the fields. Other

I do not know

Which of the following statements is how often one should use compost topdressing on an athletic field?

Never

Less than once every 5 years

Every 3-5 years

Every $1-3$ years

Once a year

More than once a year

Only if a soil test determines your soil phosphorus levels to be below environmentally critical levels and soil organic matter is low

I do not know

Which of the following statements is most correct about when to overseed athletic fields?

The spring to maintain a thick stand of grass before wear occurs.

The summer when school is not in session.

The fall to repair and maintain the current stand of grass.

The winter when there is snow on the ground to prepare for the next growing season.

Any time during the growing season where field play is anticipated.

I do not know

were tested via a $t$ test. Categorical variables differences (yes, no) between small and large groups were tested via chi-squared tests to identify significant differences $(P \leq 0.10)$ between proportions of the yes/no responses for specific questions asked of attendees using Stata (version 14.2; professional meetings, and type of jobs performed varied significantly between small- and large-group formats (Table $2)$. Given these differences, we used an ordinary least squares (OLS) regression to control for factors outside of presentation type.

The OLS model was specified as:

$Y_{i}=\beta_{0}+\beta_{1}($ respondent age $)+\beta_{2}($ years of service $)+\beta_{3}($ certification $/$ short course education $)$

$+\beta_{4}$ (some college or more education)

$+\beta_{5}$ (attend professional meeting at least once per year)

$+\beta_{6}$ (direct personnel $/$ develop budget $)$

$+\beta_{7}$ (determine purchases, maintenance, and fertility plans)

$+\beta_{8}$ (perform maintenance/fertility applications)

$+\beta_{9}$ (town has dedicated personnel $)+\beta_{10}$ (small group format)

$+\beta_{11}$ (interaction: small group format

$\times$ attend professional meeting more than once per year $)+\varepsilon$,

StataCorp, College Station, TX). However, as can be seen in Table 2, results may be a function of who attended each event. Respondent age, education levels, attendance at where $Y_{i}$ represents the difference in the number of correct answers between the pre- and posttests.

The $\beta_{10}$ and $\beta_{11}$ coefficients are the most pertinent to this article as these coefficients directly relate to our hypothesis. Given that small- and large-group variables are categorical in nature, we treat them as dummy variables. We only included one dummy variable in the model so as to avoid perfect multicollinearity (Lazaridis, 1986). The included dummy variable, in our case small group, is compared against the left out variable, large group. Thereby, $\beta_{10}$ measures whether the smallgroup presentation method provided a significantly different knowledge gain (posttest minus pretest) compared with the large-group setting. $\beta_{11}$ is included as the only interaction given that attending other educational sessions could influence the effect of knowledge gain. Several other interactions were included, but provided nonsignificant interaction coefficients $(P \leq 0.10)$ so they were excluded from the final model. The OLS model was estimated using Stata. As a caveat, the results from the OLS model and other analyses can be 
Table 2. Survey question variables for small and large treatment groups based on responses from a 2015 survey of Connecticut turfgrass professionals.

\begin{tabular}{|c|c|c|c|c|c|c|c|}
\hline \multirow[b]{2}{*}{ Variable } & \multicolumn{2}{|c|}{ Small group } & \multicolumn{2}{|c|}{ Large group } & \multirow{2}{*}{$\begin{array}{c}\begin{array}{c}\text { Small group vs. } \\
\text { large group }\end{array} \\
P \text { value }^{\mathrm{z}}\end{array}$} & \multicolumn{2}{|l|}{ Total } \\
\hline & Mean & SD & Mean & SD & & Mean & SD \\
\hline Respondent age (years) & 42.04 & 12.17 & 49.82 & 11.29 & 0.002 & 45.76 & 12.33 \\
\hline Years of service (years) & 10.48 & 10.96 & 11.18 & 6.90 & 0.718 & 10.82 & 9.16 \\
\hline Variable & $\begin{array}{c}\text { Proportional } \\
\text { response }\end{array}$ & SD & $\begin{array}{c}\text { Proportional } \\
\text { response }\end{array}$ & SD & $\begin{array}{c}\text { Small group vs. } \\
\text { large group } \\
P \text { value }\end{array}$ & $\begin{array}{c}\text { Proportional } \\
\text { response }\end{array}$ & SD \\
\hline \multicolumn{8}{|l|}{ Education } \\
\hline None & 0.88 & 0.33 & 0.36 & 0.49 & 0.000 & 0.63 & 0.49 \\
\hline Certification/short course & 0.04 & 0.20 & 0.48 & 0.51 & 0.000 & 0.25 & 0.44 \\
\hline Some college or more & 0.08 & 0.28 & 0.16 & 0.37 & 0.263 & 0.12 & 0.33 \\
\hline \multicolumn{8}{|l|}{ Attend professional meetings } \\
\hline Direct personnel/develop budgets & 0.33 & 0.48 & 0.59 & 0.50 & 0.013 & 0.46 & 0.50 \\
\hline $\begin{array}{l}\text { Determine purchases, maintenance, } \\
\text { and fertility plans }\end{array}$ & 0.38 & 0.49 & 0.68 & 0.47 & 0.003 & 0.52 & 0.50 \\
\hline $\begin{array}{l}\text { Perform maintenance/fertility } \\
\text { applications }\end{array}$ & 0.96 & 0.20 & 1.00 & 0.00 & 0.171 & 0.98 & 0.15 \\
\hline \multicolumn{8}{|l|}{$\begin{array}{l}\text { Town has dedicated personnel for } \\
\text { athletic fields }\end{array}$} \\
\hline Yes & 0.82 & 0.39 & 0.76 & 0.43 & 0.521 & 0.79 & 0.41 \\
\hline No & 0.18 & 0.39 & 0.14 & 0.35 & 0.625 & 0.16 & 0.37 \\
\hline Do not know & 0.00 & 0.00 & 0.10 & 0.30 & 0.036 & 0.05 & 0.21 \\
\hline
\end{tabular}

generalized only if our sample is representative of the overall population of turfgrass professionals in Connecticut and/or throughout the United States. However, there is no source to which we can compare our sample's make-up. The only source that gives us some idea of representability is the study by Bartholomew et al. (2015) of Connecticut turfgrass professionals. Our sample has a similar number of years on the job compared with Bartholomew et al. (2015). Other variables (i.e., methods of information and age of respondent) included in Bartholomew et al. (2015) that might allow for comparison are not the same as the questions asked in this study.

\section{Results and discussion}

Personal, professional, and departmental characteristics of the subjects participating in each dissemination method are summarized in Table 2 . Subjects participating in large-group educational sessions were generally older, more educated, and attended more professional meetings than subjects from small groups. In addition, there was a greater percentage of subjects from large-group educational sessions that directed personnel, developed budgets, and made decisions regarding purchases and fertility management plans. For instance, 33\% of attendees in small-group sessions directed personnel/developed budgets whereas $59 \%$ of large-group attendees directed personnel/developed budgets. These data indicate that the population attending large-group sessions likely consisted of more school grounds managers compared with the population attending small-group sessions.

Pre- and posteducational test scores from outreach events are shown in Table 3. Attendees from smallgroup sessions answered more questions correctly for compost topdressing before the educational session compared with after the session. Large groups saw a significant knowledge gain associated with aeration posteducational session. No significant differences in percentage correct answers for irrigation and overseeding for small and large groups were observed. Of significance within these results is the relatively low accuracy rate across both presentation styles for the pretest: $67 \%$ was the highest accuracy rate by the small group for the compost topdressing question, and $55 \%$ for the large group for the irrigation question. These results indicate that a great educational need for school grounds managers regarding overseeding, compost topdressing, aeration, and irrigation.

A key to comparing presentation types is to understand how many questions were correctly answered across methods. Small-group attendees answered two of four questions correctly on the pretest, while averaging only 1.21 questions correct on the posttest (Table 4). This drop in the number of questions answered correctly was the result of lower 
Table 3. Connecticut turfgrass professionals pre- and posttest scores on a 2015 knowledge-based survey provided in either large- or small-group setting. ${ }^{\mathrm{z}}$

\begin{tabular}{|c|c|c|c|c|c|c|}
\hline \multirow[b]{2}{*}{ Cultural practices } & \multicolumn{3}{|c|}{ Small group } & \multicolumn{3}{|c|}{ Large group } \\
\hline & Pretest (\%) & Posttest (\%) & $P$ value & Pretest (\%) & Posttest (\%) & $P$ value \\
\hline Irrigation & 54 & 50 & 0.773 & 55 & 45 & 0.546 \\
\hline Compost topdressing & 67 & 21 & 0.001 & 41 & 59 & 0.228 \\
\hline Overseeding & 21 & 13 & 0.439 & 32 & 36 & 0.750 \\
\hline Observations & 24 & 24 & & 22 & 22 & \\
\hline
\end{tabular}

${ }^{\mathrm{z}}$ Small group and large group differences were tested via a chi-squared test.

Table 4. Comparison of presentation types using knowledge-based questions from a 2015 survey of Connecticut turfgrass professionals.

\begin{tabular}{|c|c|c|c|}
\hline \multirow[b]{3}{*}{ D } & Small group & Large group & \multirow[b]{2}{*}{$P$ value ${ }^{\mathrm{z}}$} \\
\hline & \multicolumn{2}{|c|}{ Correct responses } & \\
\hline & 2.00 & 1.59 & 0.308 \\
\hline Posttest & 1.21 & 2.00 & 0.024 \\
\hline Total difference (post-pre) & -0.79 & 0.41 & 0.007 \\
\hline Number of observations & 24 & 22 & \\
\hline
\end{tabular}

${ }^{\mathrm{z}}$ Small group and large group differences were tested via a $t$-test.

posttest scores across all questions at small-group meetings, especially for the compost topdressing question which saw a $46 \%$ decrease in the number of attendees that correctly answered it (Table 3 ). In comparison, there was only a $4 \%, 20 \%$, and $8 \%$ decrease in posttest scores for irrigation, aeration, and overseeding, respectively. However, large-group attendees correctly answered 1.59 questions on the pretest and two questions on the posttest. Largegroup gains were evident with most of the questions, except irrigation, with the biggest knowledge gain coming on the aeration question.

Small-group meetings had a negative effect on knowledge gained, whereas the large-group field day had a positive effect (Table 4 ). The negative result of the small-group meeting seems counterintuitive, and it is in contrast to findings by Kline et al. (2012) and Shaw et al. (2015) which showed a targeted approach, similar to our small group method, leads to knowledge gains. However, several factors may have directly contributed to this outcome. Smallgroup meetings were free to all athletic field management staff in the district. Because the meeting was provided at no cost to each town or staff, there may have been no incentive for town employees to take the course seriously, especially by those that are not the decision-makers for the turfgrass management program. For the large-group field day, there was a nominal registration fee charged, and a higher number of decisionmakers attended. The monetary charge and increased decision responsibility may have lead largegroup attendees to value the information more than small-group attendees.

Based on those attending, it is clear that a simple comparison of means or proportions may not be a complete and accurate representation of the effects of the two programs. Using the OLS model to control for a variety of personal and job characteristics, we are able to measure the learning retention of the presentation types. From the OLS results, we find that numerous variables have a significant result $(P \leq$ 0.10 ) on knowledge gain/loss (Table $5)$. First, as the attendee's age increases, there is a 0.04 increase in the number of correct answers per year from the pre- to posttest. This amount is small, but a 10-year age increase results in almost a half a question gain (0.4) in correct answers. However, for each year of service there is a negative $(-0.05)$ impact on the number of correct answers. In essence, the older an attendee, the more questions they get correct, which may be the result of increased experience, but as length of tenure in their current job increases, there may be a tendency to do things as they have always done.
Those attendees with a certification/or short-course training had a 1.2 question increase in the number of questions answered correctly ( $\mathrm{Ta}$ ble 5 ). Furthermore, we found attendees with direct responsibilities to assign personnel or develop budgets answered 1.3 more questions correctly from the pre- to posttest. This is consistent with the expectation that attendees with decisionmaking responsibilities either are more knowledgeable about how to maintain athletic fields or were more willing to learn during the meetings.

Finally, we find that the attendees of the small-group presentation method answered 1.7 fewer questions correct compared with the large group attendees (Table 5 ). This finding is consistent with the statistical results, but provides more confidence, because other variables have been controlled (e.g., age, years of service, and job type). Our results are similar to findings of Amare (2006) and Savoy et al. (2008) that a more traditional (i.e., non-computer based presentations, podium lectures, and handouts) format provides more knowledge gain than a computer based presentation. However, our results differ from those of Beers (2005), which provided evidence that problem-based learning provided outcomes similar to traditional lectures. Based on our finding, there is evidence that the large-group meeting provided a better method to communicate knowledge gain than the small-group meeting. Most likely, this is because of the manner in which information was disseminated with little chance to divert away from the discussion topic. For instance, the large-group field day had a direct timeline of information to be covered, with limited availability to move off-topic. However, the design of the small-group meeting provided key information, but was more flexible in the range of discussion topics. 
Table 5. Ordinary least squares regression results indicating explanatory variable effect on total knowledge gain based on responses from a 2015 survey of Connecticut turfgrass professionals.

\begin{tabular}{|c|c|c|c|}
\hline Variables $^{\mathrm{z}}$ & Coefficient & SE & $P$ value \\
\hline Respondent age & 0.043 & 0.022 & 0.061 \\
\hline Years of service & -0.049 & 0.028 & 0.088 \\
\hline \multicolumn{4}{|l|}{ Education } \\
\hline Certification/short course & 1.162 & 0.567 & 0.049 \\
\hline Some college or more & 1.048 & 0.797 & 0.198 \\
\hline \multicolumn{4}{|l|}{ Attend professional meetings } \\
\hline At least once per year & -1.654 & 0.861 & 0.064 \\
\hline \multicolumn{4}{|l|}{ Type of job } \\
\hline Direct personnel/develop budgets & 1.294 & 0.731 & 0.087 \\
\hline $\begin{array}{l}\text { Determine purchases, maintenance, and fertility } \\
\text { plans }\end{array}$ & -0.623 & 0.733 & 0.402 \\
\hline Perform maintenance/fertility applications & -2.332 & 1.683 & 0.176 \\
\hline \multicolumn{4}{|l|}{ Town have dedicated personnel for athletic fields } \\
\hline Yes & 0.581 & 0.546 & 0.296 \\
\hline $\begin{array}{l}\text { Small group (compared with base variable: } \\
\text { large group) }\end{array}$ & -1.653 & 0.925 & 0.084 \\
\hline $\begin{array}{l}\text { Interaction: attend meeting once or more } \mathrm{x} \\
\text { small group }\end{array}$ & 1.209 & 1.151 & 0.302 \\
\hline Constant & 1.108 & 2.101 & 0.602 \\
\hline Overall model F-statistic & 2.900 & & \\
\hline Prob $>$ F & 0.010 & & \\
\hline Number of observations & 43 & & \\
\hline$R^{2}$ & 0.508 & & \\
\hline Adj. $R^{2}$ & 0.333 & & \\
\hline
\end{tabular}

${ }^{\mathrm{z}}$ Base categories: education = none; professional meeting attendance = less than once per year; town have dedicated personnel $=$ no/not sure; presentation type = large group

The results of this study do not imply that the large-group meeting should always be chosen instead of the small-group meeting. Our results indicate that for dissemination of specific information, the large-group meeting resulted in greater learning. However, there may be situations in which small-group meetings are preferable to large-group meetings for improving knowledge gain, especially if project cost, time, or hands-on demonstrations by participants is required. Hands-on demonstrations can be offered at large-group meetings, but the amount of individualized time is limited because of a larger number of attendees. Furthermore, as noted by Milburn et al. (2010), one-on-one contact is a highly valued method to engage and disseminate information.

\section{Conclusions}

Disseminating information is critical to the mission of land grant universities. However, the most effective method to educate school athletic field managers is not well understood. Our results indicate that participants in the large group had greater knowledge retention than the small-group meeting participants. We expect that these differences are due to the structure of the small-group meeting, whereby small-group attendees had more flexibility to discuss topics in turf management affecting them directly. The small-group format provided time for the University of Connecticut turf faculty to answer questions in depth and provide further explanation where necessary. Straying off the four topics in the education program may have resulted in less time targeting the four main topics compared with the large group. Large-group attendees had little opportunity to deviate from the main subject matter because of the program format. Although the format allowed for some questions, delivery of information was in a lecture-type format. However, the value of smallgroup meetings should not be discounted, especially when athletic field managers and staff need information specific to their situation. Further, small-group meetings potentially allow for more training opportunities for staff as they are more likely to attend. Overall, when disseminating general information, the large-group meeting format most likely provides a better method of delivery when focusing on key points. Additional research comparing other presentation methods and various types of people is needed to increase our understanding of the best ways to present extension information.

\section{Literature cited}

Alarcon, W.A., G.M. Calvert, J.M. Blondell, L.N. Mehler, J. Sievert, M. Propeck, D.S. Tibbetts, A. Becker, M. Lackovic, S.B. Soileau, R. Das, J. Beckman, D.P. Male, C.L. Thomsen, and M. Stanbury. 2005. Acute illnesses associated with pesticide exposure at schools. J. Amer. Medical Assn. 294(4):455-465.

Amare, N. 2006. To slideware or not to slideware: Students' experiences with PowerPoint vs. lecture. J. Tech. Writ. Commun. 36(3):297-308.

Bartholomew, C., B.L. Campbell, and V. Wallace. 2015. Factors affecting athletic field quality after pesticide bans: The case of Connecticut. HortScience 50:99-103.

Beers, G. 2005. The effect of teaching method on objective test scores: Problembased learning versus lecture. J. Nurs. Educ. 44(7):305-309.

Chomiak, J., A. Junge, L. Peterson, and J. Dvorak. 2000. Severe injuries in football players. Influencing factors. Amer. J. Sports Med. 28(5):S58-S68.

Cutz, G., B. Campbell, K.K. Filchak, E. Valiquette, and M.E. Welch. 2015. Impact of a $4-\mathrm{H}$ youth development program on at-risk urban teenagers. J. Ext. 53(4):4FEA8. 13 June 2018. <https:// www.joe.org/joe/2015august/pdf/ JOE_v53_4a8.pdf $>$.

Dest, W.M. and J.S. Ebdon. 2011. Study: Natural turf use levels. SportsTurf 27:811.

Dugard, P. and J. Todman. 1995. Analysis of pre-test-post-test control group designs in educational research. Educ. Psychol. 15(2):181-198.

Edwards, C.A. 1993. The impact of pesticides on the environment, p. 13-46. In: D. Pimentel and H. Lehman (eds.). The pesticide question: Environment, economics, and ethics. Routledge Chapman Hall, New York, NY.

Gilden, R., E. Friedmann, B. Sattler, K. Squibb, and K. McPhaul. 2012. Potential health effects related to pesticide use on athletic fields. Public Health Nurs. 29(3): 198-207.

Harper, J.C., C.A. Morehouse, D.V. Waddington, and W.E. Buckley. 1984. 
Turf management, athletic field conditions, and injuries in high school football. Pennsylvania State Univ., College Agr., Agr. Expt. Sta. Prog. Rpt. 384.

Henderson, J., V. Wallace, and J. Campbell. 2013. Best management practices for pesticide free cool season athletic fields. 13 June 2018. <http://www.turf.uconn.edu/ pdf/research/factsheets/OrganicFields BMP_2013.pdf? $11 \mathrm{r}=\mathrm{kaiit} 7 \mathrm{cab} \&$ oeidk= a07e81i48ky0lbfed07\&oseq=a017dfxgjiuci $>$.

Kennelly, M.M. and J.A. Hoyle. 2015. Assessing impact of online delivery of turfgrass and landscape information. J. Ext. 53:5TOT4. 13 June 2018. <https://www. joe.org/joe/2015october/tt4.php>.

Kline, T.R., H. Kneen, E. Barrett, A. Kleinschmidt, and D. Doohan. 2012. Adapting extension food safety programming for vegetable growers to accommodate differences in ethnicity, farming scale, and other individual factors. J. Ext. 50(1):1IAWl. 13 June 2018. <https: //www. joe.org/joe/2012february/pdf/JOE_v50_ liwl.pdf>.

Kudryavtsev, A., M.E. Krasny, and J.B. Walther. 2010. Dissemination of outreach education programs: In-person and computer-mediated strategies. J. Ext. 48(5):5FEA4. 13 June 2018. <https:// www.joe.org/joe/2010october/a4. php>.

La Barge, G. 2007. Pre- and post-testing with more impact. J. Ext. 45(6):6IAWl. 13 June 2018. <https://joe.org/joe/ 2007 december/iwl.php>.

Lazaridis, A. 1986. A note regarding the problem of perfect multicollinearity. Qual. Quant. 20(2/3):297-306.
Mathiasen, L., K. Morley, B. Chapman, and D. Powell. 2012. Using a training video to improve agricultural workers' knowledge of on-farm food safety. J. Ext. 50(1):1FEA6. 13 June 2018. <https:// www.joe.org/joe/2012february/a6 . php>.

Matson, P.A., W.J. Parton, A.G. Power, and M.J. Swift. 1997. Agricultural intensification and ecosystem properties. Science 277(5325):504-509.

Milburn, L.S., S.J. Mulley, and C. Kline. 2010. The end of the beginning and the beginning of the end: The decline of public agricultural extension in OntarioJ. Ext. 48(6):6FEA7. 13 June 2018. <https:// www.joe.org/joe/2010december/pdf/ JOE_v48_6a7.pdf>.

Miller, N.A. and J. Henderson. 2012. Organic management practices on athletic fields: Part 1. The effects on color, quality, cover, and weed populations. Crop Sci. 52(2):890-903.

Nayak, R., D. Tobin, J. Thomson, R. Radhakrishna, and L. LaBorde. 2015. Evaluation of on-farm food safety programming in Pennsylvania: Implications for extension. J. Ext. 53(1):1FEA9. 13 June 2018. <https://www.joe.org/joe/ 2015february/a9.php>.

Nyhan, R.C. and M.G. Alkadry. 1999. The impact of school resources on student achievement test scores. J. Educ. Finance 25(2):211-227.
Orchard, J. 2002. Is there a relationship between ground and climatic conditions and injuries in football? Sports Med. 32(7):419-432.

Pimentel, D., H. Acquay, M. Biltonen, P. Rice, M. Silva, J. Nelson, V. Lipner, S. Giordano, A. Horowitz, and M. D'Amore. 1992. Environmental and economic costs of pesticide use. Bioscience 42(10):750760.

Savoy, A., R.W. Proctor, and G. Salvendy. 2008. Information retention from PowerPoint and traditional lectures. Comput. Educ. 52(4):858-867.

Shaw, A., C. Strohbehn, L. Naeve, P. Domoto, and L. Wilson. 2015. Knowledge gained from good agricultural practices courses for Iowa growers. J. Ext. 53(5):5RIB3. 13 June 2018. <https:// www.joe.org/joe/2015october/rb3. php>.

StataCorp. n.d. Tabulate twoway-Two way table of frequencies. 13 June 2018. <https://www.stata.com/manuals 13/ rtabulatetwoway.pdf>.

State of Connecticut. 2005. Public Act 5252. 13 June 2018. <http://www.cga.ct. gov $/ 2005 / \mathrm{act} / \mathrm{pa} / 2005 \mathrm{pa}-00252$ r00sb-00916-pa.htm>.

Wallace, V., C. Bartholomew, and J.H. Campbell. 2016. Turf manager response to changing pesticide regulations. HortScience 51:394-397. 